\title{
Experimental biogeography: the role of environmental gradients in high geographic diversity in Cape Proteaceae
}

\author{
Andrew M. Latimer · J. A. Silander Jr • A. G. Rebelo • \\ G. F. Midgley
}

Received: 20 May 2008 / Accepted: 5 January 2009 / Published online: 5 February 2009

(C) The Author(s) 2009. This article is published with open access at Springerlink.com

\begin{abstract}
One of the fundamental dimensions of biodiversity is the rate of species turnover across geographic distance. The Cape Floristic Region of South Africa has exceptionally high geographic species turnover, much of which is associated with groups of closely related species with mostly or completely non-overlapping distributions. A basic unresolved question about biodiversity in this global hotspot is the relative importance of ecological gradients in generating and maintaining high geographic turnover in the region. We used reciprocal transplant experiments to test the extent to which abiotic environmental factors may limit the distributions of a group of closely related species in the genus Protea (Proteaceae), and thus elevate species turnover in this diverse, iconic family. We tested whether these species have a "home site advantage" in demographic rates (germination, growth, mortality), and also parameterized stage-structured demographic models for the species. Two of the three native species were predicted to have a demo-
\end{abstract}

Communicated by Katherine Gross.

Electronic supplementary material The online version of this article (doi:10.1007/s00442-009-1275-3) contains supplementary material, which is available to authorized users.

\section{A. M. Latimer $(\square)$}

Department of Plant Sciences, University of California,

One Shields Avenue, Davis, CA 95616, USA

e-mail: amlatimer@ucdavis.edu

\section{J. A. Silander Jr}

Department of Ecology and Evolutionary Biology,

University of Connecticut, Storrs, CT 06269, USA

A. G. Rebelo · G. F. Midgley

South African National Biodiversity Institute,

Private Bag X7, Claremont 7735, Cape Town, South Africa graphic advantage at their home sites. The models also predicted, however, that species could maintain positive population growth rates at sites beyond their current distribution limits. Thus the experiment suggests that abiotic limitation under current environmental conditions does not fully explain the observed distribution limits or resulting biogeographic pattern. One potentially important mechanism is dispersal limitation, which is consistent with estimates based on genetic data and mechanistic dispersal models, though other mechanisms including competition may also play a role.

Keywords Cape Floristic Region - Species turnover . Endemism $\cdot$ Proteaceae $\cdot$ Experimental biogeography

\section{Introduction}

The Cape Floristic Region (CFR) of South Africa has high local species diversity for a temperate region, but the region's extraordinarily high geographical species turnover contributes substantially to the total plant species diversity in the region, raising it to a level as high as some tropical forests (like Panama, the CFR contains $\sim 9,000$ species in $\sim 90,000 \mathrm{~km}^{2}$ ) (Goldblatt and Manning 2000; Simmons and Cowling 1996). A major component of this species turnover is replacement of individual species by closely related, ecologically similar species (Linder 1985; Linder et al. 2006; Rebelo 2006; Richardson et al. 2001). Many such groups of closely related, allopatric species are found in the region's most diverse lineages, including the Proteaceae, Restionaceae, and Ericaceae (Linder 2003, 2005; Rebelo 2001). A basic question about what drives the high biodiversity in this region is to what extent this pattern reflects local ecological adaptation along environmental 
gradients-versus differentiation by drift of isolated populations (Cowling and Lombard 2002; Cowling and Proches 2005; Cowling et al. 1996; Linder 1985), or higher speciation rates driven by life history traits (Wisheu et al. 2000).

Previous studies of the CFR have identified two classes of factors driving high species turnover: extraordinarily high environmental heterogeneity and strong gradients, inducing adaptation to contrasting environments and environmental constraints on distributions (Ellis and Weis 2006; Goldblatt and Manning 2000; Linder 2003; Linder and Mann 1998); and exceptionally low dispersal among subregions, leading to local isolation and topographic constraints on distributions (Barraclough 2006; Cowling and Lombard 2002; Latimer et al. 2005; Linder 1985). But despite the apparent importance of geographic species turnover in the region (Cowling and Lombard 2002; Goldblatt and Manning 2002), experimental and theoretical work on diversity in the region has focused mainly on coexistence of sympatric species (Anderson 1996; Bond et al. 1995; Yeaton and Bond 1991). Past field work has accordingly mostly involved sympatric species associated with different soil types or fire regimes-i.e., ecological contrasts across short, steep gradients (Bond 1984; Bond et al. 1992; Bond and Midgley 2001; Richards et al. 1995, 1997a,b). In contrast, the role of turnover from one geographic area to another among similar, often closely related species has been little explored.

This work builds on previous work on experimental testing of the role of environment in setting distribution limits-including for example the classic work on Latuca serriola (prickly lettuce) in Britain (Prince and Carter 1985) that found individual plants grew well outside the contemporary distribution limits of that species. More recent work using observational data, but without experimental transplants, has produced equivocal results, some studies finding superior population performance at the range center than the edge (Angert 2006), some not (Norton et al. 2006; Stokes et al. 2004). While there is a long tradition in plant ecology of using transplant experiments and demographic models to explore species distribution limits (Prince and Carter 1985), few studies have used experiments to parameterize demographic models for species outside their natural distributions (Gaston 2003), and thus answer more convincingly the fundamental question of how strongly current environmental conditions limit species distributions, a frequent assumption in equilibrium models of community assembly and species distributions.

Here we present results from the first direct experimental investigation of the role of regional-scale ecological gradients in enhancing the CFR's high geographic turnover rates. We focus on a representative group of closely related, yet almost completely allopatric shrub species in the genus Protea (Proteaceae). Using reciprocal plantings of these species (i.e., experimental biogeography), and demographic models parameterized from the results of this experiment, we tested the ability of these species to germinate, survive, grow and thereby maintain positive population growth rates across a range of environmental conditions.

\section{Materials and methods}

As a representative group, we selected the white proteas, a monophyletic group within the genus Protea (L.) (Rebelo 2001; Reeves 2001). We selected this group because it displays the geographical pattern typical of many CFR clades: little distributional overlap (Fig. 1), and no obvious strong local environmental shifts associated with the transition from one species distribution to another (Linder 1985; Rebelo 2001). We included in the experiment four white protea species, including three species endemic to the region, Protea aurea, Protea mundii, and Protea punctata, and one, Protea subvestita, which occurs almost exclusively in the summer-rainfall region to the east of the CFR. We included $P$. subvestita, which occurs naturally in an environment clearly distinct from those of the other species, with its summer-concentrated rainfall, to provide a "baseline" against which to assess ecological differences among the relatively similar CFR endemics.

The environmental range of the CFR endemic species, based on some 60,000 presence-absence records for proteas across their entire CFR distributions (Rebelo 2006), is summarized in Supplementary Fig. 2:1. Four environmental variables are displayed, representing minimum and maximum temperatures (July minimum and January maximum temperature), total moisture availability (mean annual precipitation) and seasonality of moisture availability (summer soil moisture days) (Schulze 1997). As is evident in the figure, the species' environmental envelopes defined by these variables overlap to some extent, suggesting a priori that they may be relatively ecologically similar, although not identical (Supplementary Fig. 2:1).

As is typical for bird-pollinated plant species in the region, flowers of all the CFR endemic species in the group are pollinated by a widespread primary pollinator, the Cape sugarbird Promerops cafer, and also by several species of sunbird (Nectarina spp.) (Avian Demography Unit 2006; Lotz and Nicholson 1996; Rebelo 2001). It has been suggested that differences in fire return times may influence species coexistence in the region (Bond 1984; Bond et al. 1995), but in the case of these species, differences in fire regime are extremely unlikely to explain their failure to occur in the same locales. An analysis of the best fire history data for the region, the CapeNature wildfire database, which records fires in public natural areas across the region, shows that fire return time varies much more within the 
ranges of each white protea species than among their distributions (Forsyth and van Wilgen 2007; Wilson et al., in review). Thus there is little chance that fire gradients play an important role in limiting the distributions of these species at the regional and subregional scales, although they may play a role at the local and landscape scales where most frequency variation occurs.

We selected experimental field sites to represent conditions collectively spanned by the distributions of the three CFR-endemic white protea species (Fig. 1). Two of the sites (Nature's Valley- $P$. mundii, Swartberg- $P$. punctata) were adjacent to natural populations of white proteas; two others (Jonaskop 1,550 m-P. punctata; Jonaskop $950-P$. aurea) were within $5 \mathrm{~km}$ of natural populations. Collectively, the sites were selected to cover a range of elevations, temperatures, and mean annual precipitations, and precipitation seasonality. Table 1 provides values of several key environmental variables for each experimental site, using values drawn from gridded 1-arcminute-scale meanclimate GIS data sets (Schulze 1997). Supplementary Fig. 2:1 displays the locations in environmental space of the five transplant plots, showing qualitatively how repre- sentative (along these axes) the sites are of the distributions of the species (Table 1).

At Jonaskop, in addition to the 950-m and 1,550-m sites, we established one site at 744-m elevation, to test the species' performance under drier, hotter conditions (Table 1). This site lies at lower edge of fynbos where it grades into drier-climate vegetation dominated by Asteraceae and succulents-i.e., semi-arid succulent karoo (Agenbag 2006). We included this "extreme" site to ensure that even if all the species did well at all the less arid sites, we would still be able to test drought-related physiological limitation on these species, and to see whether this limitation differed among species. Collectively, the set of five field sites encompassed the range of climatic and elevational conditions representative of the CFR species in this clade (compare Table 1, Supplementary Fig. 2:1).

All these species occur naturally across multiple soil types, including very nutrient-poor sandstone soils as well as somewhat more fertile soils derived from shale; thus they are not rigidly confined by soil type (Rebelo 2001), and a priori, soil type specialization cannot explain the large-scale geographic separation of the white proteas

Fig. 1 Distributions of white proteas in the Cape Floristic Region. Each point represents a location from the Protea Atlas Project database at which white protea species were observed

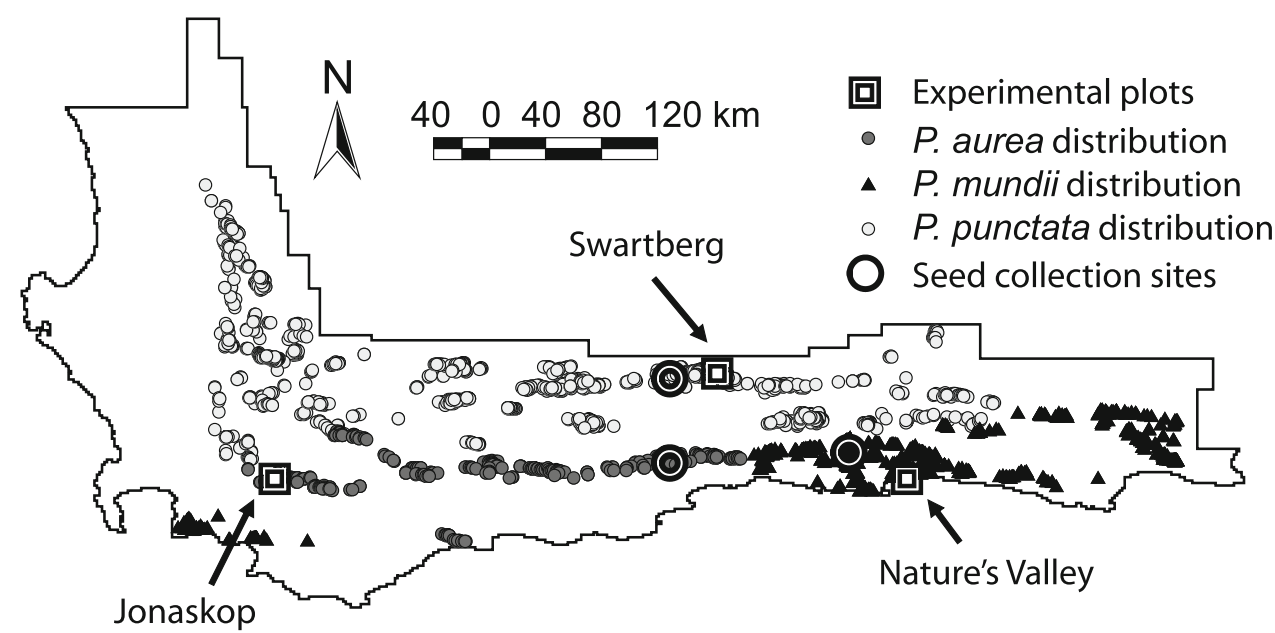

Table 1 Environmental attributes of plot locations for the white protea reciprocal planting experiment, from Schulze (1997). Elev. Elevation, precip. precipitation

\begin{tabular}{lccccc}
\hline Site & Elev. $(\mathrm{m})$ & July min. temp. ${ }^{\mathrm{a}}\left({ }^{\circ} \mathrm{C}\right)$ & Jan. max. temp. $\left({ }^{\circ} \mathrm{C}\right)$ & Mean annual precip. $(\mathrm{mm})$ & Summer soil moisture $^{\mathrm{c}}$ \\
\hline Nature's Valley & 237 & 7.3 & 26.9 & 1,142 & 36.7 \\
Swartberg Pass & 1,400 & -0.1 & 27.9 & 840 & 28 \\
Jonaskop 744 m & 744 & 5.3 & 27.0 & 438 & 71 \\
Jonaskop 950 m & 950 & 4.4 & 24.1 & 782 & 17 \\
Jonaskop 1550 m & 1,550 & 3.0 & 21.3 & 1,407 & 27
\end{tabular}

\footnotetext{
a July minimum temperature (temp.) is the long-term mean minimum (min.) temp. for the coldest month

b January (Jan.) maximum temp. is mean maximum (max.) temp. for the warmest month

${ }^{c}$ Summer soil moisture is the number of days during December, January and February when modeled soil moisture exceeds a threshold for unstressed photosynthesis and growth. Since moisture is typically available at all sites during the winter months, summer soil moisture also reflects the strength of rainfall seasonality and max. drought stress
} 
clade. This is unlike the case for some other CFR Proteaceae species, for which strong soil-type transitions (e.g., acid/alkaline soils) have been shown to be a critical factor increasing species segregation on a local scale (Cowling 1990; Richards et al. 1997b; Rouget et al. 2003). Our experimental design choice focused on climatic factors, while controlling for soil type. To limit potential confounding of climatic and soil-related effects, we placed all sites on the same soil type: low-fertility sandy soils derived from the same underlying sandstone bedrock (Goldblatt 1997). Analysis of bulked samples from the plots by Matrocast Soil Laboratories, Cape Town, confirmed that soils at all sites were acidic $(\mathrm{pH} \leq 5.1)$, and all contained low nutrient levels $(\leq 4 \mathrm{mg} / \mathrm{kg} \mathrm{P})$.

Seeds of the white protea species $P$. mundii, P. punctata, $P$. aurea, and $P$. subvestita were gathered from natural populations (see Fig. 1). Seedlings for transplantation were grown by germinating seeds outdoors at the South African National Biodiversity Institute, Kirstenbosch in flats containing low-fertility sandy medium, starting in early May 2003 (Brown and Botha 2004). After germination, seedlings were kept watered and placed in direct sunlight. In July 2003, we planted the sites with seeds and seedlings of each species. At each site, we planted three $1-\mathrm{m}^{2}$ plots with 16 seedlings per replicate per species (i.e., 48 total seedlings per species per site). At each site except Swartberg, we also planted three replicate $1-\mathrm{m}^{2}$ plots with 25 seeds per replicate per species (i.e., 75 total seeds per species per site). At Swartberg, only the seedlings were planted due to lack of sufficient additional seeds.

The full set of five sites thus included at least one representative "home site" for each of the three endemic species, at least two sites outside the distribution of each species (and representative of conditions for some other species), and one site thought a priori to be outside the conditions tolerable to any of the species. For testing the hypothesis that the species are restricted to their home ranges by abiotic environmental conditions, the design thus provided replication at two levels: multiple plots within sites to capture small-scale environmental variation, and multiple sites outside the current distributions of the species, to capture large-scale variation. If the species performed well in replicated treatments at multiple sites outside their current distribution limits, this would demonstrate that the species are not limited by abiotic environmental factors at the establishment stage, thought to be the critical stage for these species (Bond 1984; Bond and Midgley 2001).

To obtain estimates of gene flow within and among populations of these species, we extracted DNA from leaves of 15 individuals from each of five populations of $P$. punctata. We developed six variable microsatellite markers for $P$. punctata and scored these for sampled individuals (Latimer 2006; A.M. Latimer, unpublished data). Individuals within populations were sampled on a transect across the population at a range of distances apart. Populations were spaced at a range of distances, ranging from 5 to $\sim 400 \mathrm{~km}$ apart.

Measurements and lab analysis

Soon after transplanting, in early August 2003, we measured initial heights of seedlings to provide a baseline for relative growth rates. Germination and mortality of seedlings were recorded in October 2003, January 2004, August 2004, and August 2005. Heights and stem diameters were also measured on the latter three dates. At the conclusion of the experiment in August 2005, we cut all living plants at ground level and harvested them. For a randomly selected subsample of individuals from each subplot, we also ground three leaves and had them analyzed for $\mathrm{C}$ isotope ratio and $\mathrm{N}$ content at the University of California Berkeley Center for Stable Isotope Biogeochemistry.

Six microsatellite markers for sampled $P$. punctata individuals were scored using an ABI 3100 capillary sequencer and Genotyper software to hand-score allele lengths (Latimer 2006). Genetic parameters and gene dispersal estimates were obtained using the software SPAGeDi (Hardy and Vekemans 2002) and Hickory (Holsinger and Lewis 2003).

\section{Statistical analysis}

If ecological differences among the white protea species are important in separating them geographically, the species should each exhibit performance contrasts among sites. In particular, we would expect species to perform relatively poorly at the sites outside their native distributions. Even if ecological differences are not strong, we would also expect that each species would be adapted to some extent to its native conditions, so that it would out-perform the other species under those conditions. We took two approaches in analyzing the results: first, we analyzed plant performance measurements directly to test for differences in these individual demographic parameters across sites for each species; and second, we parameterized demographic models to integrate the experimental observations and predict how populations of each species would fare at each site. These models were fitted by maximum likelihood methods in S-Plus 6.2 (Insightful 2003) using the libraries survival, nlme, and MASS, which use gradient descent algorithms to find maximum-likelihood estimates, or in the case of the generalized linear mixed models for mortality, penalized quasi-likelihood estimates (Pinheiro and Bates 2000; Venables and Ripley 2002).

\section{Direct comparisons of performance measurements}

Mortality of the transplanted seedlings was analyzed using parametric survival analysis, which can accommodate the 
interval-censored data generated by periodic site visits over the 2 years of the experiment (Beckage and Clark 2003). To visualize survival curves, nonparametric Kaplan-Meier estimates of the survival curve for each species and site were obtained (Turnbull 1974; Venables and Ripley 2002). For formal comparison of treatment effects, parametric survival functions were fitted to the survival data for each species/site combination (Beckage and Clark 2003).

We compared growth of transplanted seedlings using linear mixed models to analyze seedling final biomass. Species were modeled separately, to compare the performance of each species across sites. We included site as a fixed effect, since the sites represented environmental treatments selected a priori: the experiment was designed to compare how species performed within conditions representative of their natural distributions with how they performed elsewhere. In order to assess, and quantify, small-scale random variability in the conditions experienced by the plants within each site, we included random effects for the replicated plots (i.e., the three seed and three seedling plots for each species) within each site.

Observed germination for seeds was analyzed using random effects logistic regression. We modeled germination for each species separately, to compare performance across sites, then constructed an all-species model including species and site fixed effects. All these models included random effects for the subplots, and were fitted using the function glmmPQL() (Venables and Ripley 2002). Finally, we also used mixed models to compare species stable $\mathrm{C}$ isotope ratios $\left(\delta^{13} \mathrm{C}\right)$ among species and across sites, to check whether the plants were experiencing different levels of water availability at different sites, and whether particular species were responding differentially to this aridity gradient.

For each set of contrasts for a demographic parameters (e.g., the six possible contrasts among the four transplanted species for growth rate), the $P$-values were adjusted for multiple comparisons using the Bonferroni method (Snedecor and Cochran 1989). This approach is overly conservative, but there is no clearly optimal way to correct for multiple comparisons in this context, so Bonferroni was selected for its simplicity. Response and continuous explanatory variables were log-transformed to homogenize variance.

\section{Demographic modeling}

We constructed stage-structured matrix models of the population dynamics of the species (Supplementary Fig. 1:1). For the parameters we observed in the experiment, germination, seedling survival, second-year survival, and growth rate, we used the mean values measured for each species by site combination (Supplementary Table 1:1). For the other parameters, fecundity, adult mortality, and seed survival, we used estimates from independent observations and from the litera- ture, then assessing the sensitivity of the models to these estimates by also running models using minimum and maximum reasonable values for these parameters (Skalski et al. 2005; Morris and Doak 1998, estimating adult mortality; Forbis and Doak 2004; Silander 1983, estimating plant fecundity.

These species experience two basic kinds of year with different life history consequences: years with fire, and years without fire. The matrices for these two kinds of years are different. In years without fire, seeds do not germinate, but all other life transitions occur. Seedlings grow to adulthood, and reproductive adults produce seeds which they store in cones as an aerial seed bank - they are serotinous. In fire years, the adult plants are killed, seeds drop and the viable surviving seeds germinate. Adult fecundity in fire years is zero, because even if a fire occurs late, after seed has been set, the seeds are not viable until cured for several months (i.e., until the following year) (Supplementary Fig. 1:1).

Because fire return times in fynbos are variable, we used a stochastic fire regime to determine when fires would occur (and thus when to apply the fire matrix) (Tuljapurkar 1997). We drew fire return times from a normal distribution with a mean of 19 and SD of 5 years, which were checked against estimates of mean fire intervals obtained from the extensive fire database ( 2000 fires for 70 years over $\sim 40,000 \mathrm{~km}^{2}$ ) compiled by the provincial land management agency CapeNature (Forsyth and van Wilgen 2007), and against modeled fire return times (Wilson et al., in review). To reflect fuel limitation on fire immediately following a previous fire, we truncated the distribution at a minimum return time of 5 years.

In support of the model assumption that germination occurs only after fire, we note that almost all germination occurred in the first 5 months of the experiment (200 of 211 total observed germinants), and no germination occurred in the second year, despite the wetter winter in the second year (2004). This failure of seeds to germinate after a year's dormancy suggests that the standard simple model of recruitment in these species-an even-aged cohort recruited in the year of fire (Goldblatt and Manning 2000) — is reasonably realistic for reseeding fynbos proteas.

To obtain estimated population growth rates for each species at each transplant site, we ran these stochastic matrix models for 5,000 time steps, discarding the initial 500 time steps to remove transient dynamics, and obtained the mean discrete growth rate [i.e., $\log (\lambda)]$ value across the remaining simulated steps as $E\left[\log \left(N_{t} / N_{t-1}\right)\right]$ (Caswell 2001). To determine how stochastic variation in fire return times affected growth rate, we ran these simulations 100 times and used the mean as our estimate of $\log (\lambda)$. We checked the sensitivity of $\log (\lambda)$ to parameter estimates for each species $\times$ site combination by reducing the parameter values by 0.01 , one at a time, rerunning the simulation, and recording the change in $\log (\lambda)$ (Supplementary Table 1:2) 
(Tuljapurkar 1997). Finally, to test how much changing the values of our estimated parameters would affect our predicted population growth rates, we ran models with the lowest and highest values we believed to be reasonable for each individual parameter (Supplementary Table 1:1; see ESM1 for details of parameterization).

\section{Results}

\section{Mortality}

Only one species survived best at the site most representative of its native distribution (home site) - P. aurea at Jonaskop $950 \mathrm{~m}$ (Fig. 2). $P$. mundii (Nature's Valley) and $P$. punctata (Swartberg) had no statistically distinguishable survival advantages at their representative home sites (Fig. 2). P. subvestita had significantly lower survival than the other species (two-tailed $t$-tests, Bonferroni correction). Variation in survival among replicate plots within sites was substantial, consistent with the usual pattern in field studies of plant establishment, reflecting the effects of environmental variability at the smallest spatial scales (Beckage and Clark 2003; Ibanez et al. 2007).

\section{Growth}

Comparison of growth across the sites showed that biomass of one of the three native CFR species- $P$. mundii-was significantly highest at its representative home site (Supplementary Fig. 2:2). In contrast, $P$. aurea attained significantly lower biomass at its representative home site than at $P$. punctata's (Fig. 3). P. punctata's biomass at its representative site was not significantly different than at the representative home sites of the other CFR native species (Fig. 3). P. subvestita, the non-native species, had far lower biomass than all the other species (Fig. 3).

\section{Germination}

The high-elevation native species $P$. punctata exhibited significantly higher germination rates at the higher-elevation,
Fig. 2 a-d Nonparametric survival trajectories for white protea species. The representative "home sites" for the three native species are indicated by asterisks. Different letters indicate significant differences among sites for each species $(P<0.05)$

\section{a) Protea aurea}

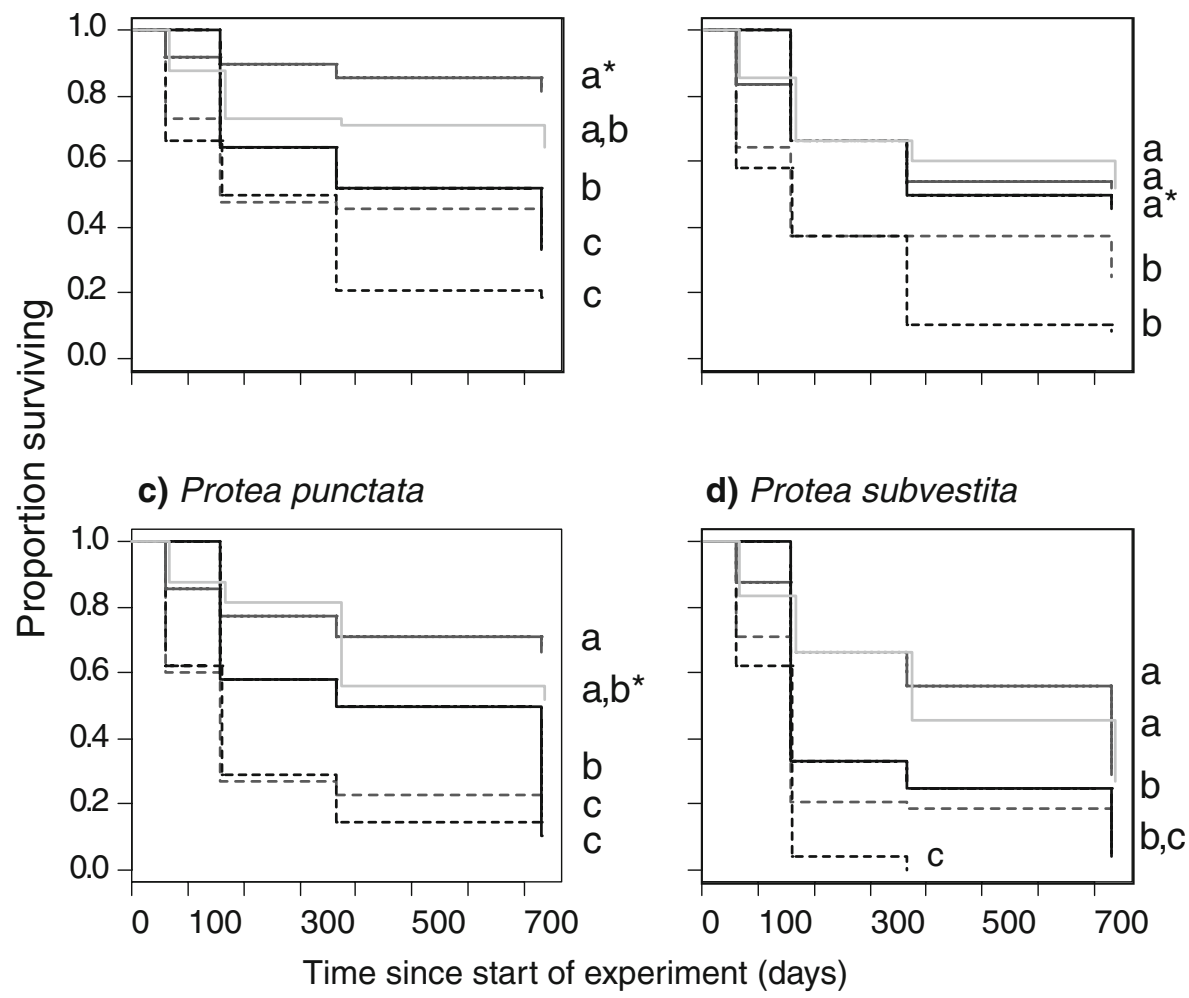


Fig. 3 a-d Comparison of biomass across sites for transplants of each white protea species. The representative home sites for the three native species are indicated by asterisks. Different letters indicate significant differences among sites for each species $(P<0.05)$. Error bars are SEs

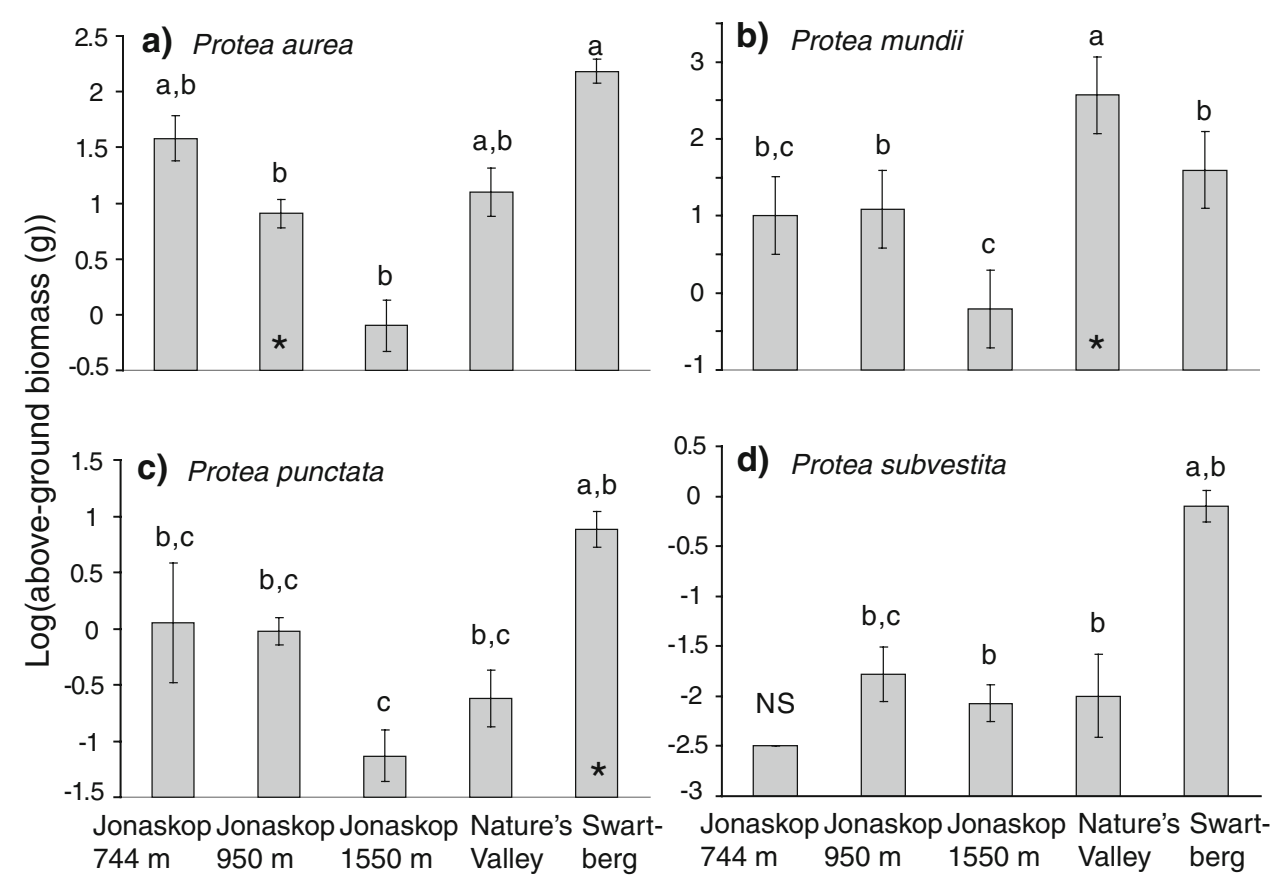

cooler sites (Jonaskop $950 \mathrm{~m}$ and representative home site Jonaskop 1,550 m) than at the lower-elevation, warmer sites (Nature's Valley and Jonaskop $744 \mathrm{~m}$ ) (Supplementary Fig. 2:2). Only $P$. aurea and $P$. mundii germinated at the driest site (Jonaskop $744 \mathrm{~m}$ ), and only these same two species recruited substantial numbers of surviving seedlings at the warm, coastal Nature's Valley site ( $P$. mundii's representative home site) (Supplementary Fig. 2:2). Thus, the other species - the high-elevation native and the nonendemic-appear to be unable to recruit new seedlings under the warmer conditions at these two sites. Two of the species, $P$. mundii and $P$. subvestita, had no significant differences in germination across sites, and $P$. aurea had only one significant site difference, favoring its representative home site (Supplementary Fig. 2:2).

\section{Aridity responses}

The three species tested, $P$. aurea, $P$. mundii, and $P$. punctata, all showed a strong physiological response to aridity. Their $\mathrm{C}$ isotope ratio values increased with increasing water limitation in an apparently linear way (Supplementary Fig. 2:3). A mixed-model analysis of covariance of $\delta^{13} \mathrm{C}$ values with species fixed effects, and precipitation, temperature, fertility and site and subplot random effects showed that $P$. mundii had significantly more negative values of $\delta^{13} \mathrm{C}$ than the other species (Table 2). Precipitation and temperature significantly influenced water use efficiency, as indicated by $\delta^{13} \mathrm{C}$, while soil parameters did not have an effect (results not shown).
Table 2 Coefficients for explanatory variables in mixed model for the stable C isotope ratios of the white protea species Protea aurea, Protea mundii, Protea punctata, and Protea subvestita

\begin{tabular}{lrrrr}
\hline Variable & \multicolumn{1}{c}{ Value } & $1 \mathrm{SE}$ & \multicolumn{1}{c}{-value } & $P$-value \\
\hline (Intercept) & -4.896 & 1.782 & -2.748 & 0.0087 \\
Species (P. mundii) & -0.658 & 0.244 & -2.695 & 0.0102 \\
Species (P. punctata) & 0.442 & 0.245 & 1.801 & 0.0791 \\
Species (P. subvestita) & 0.997 & 0.491 & 2.029 & 0.0489 \\
Mean annual precipitation & -3.261 & 0.305 & -10.686 & $<0.0001$ \\
C:N ratio & -0.461 & 0.227 & -2.032 & 0.0482 \\
\hline
\end{tabular}

Demographic modeling results

Comparing population growth rates across species, two of the three native species, $P$. aurea and $P$. mundii, had higher predicted population growth rates than the other species at their representative home sites (Fig. 4). P. punctata, the slower-growing, high elevation species, had the secondhighest predicted population growth rate at its representative home site of Swartberg (Fig. 4). Comparing growth rates across sites for each species, we find again that the same two native species, $P$. aurea and $P$. mundii, have the highest predicted rates at their representative home sites, while $P$. punctata had the highest predicted rate at the home site of $P$. aurea (Fig. 4). At the most arid site, Jonaskop $744 \mathrm{~m}$, all species but $P$. aurea, which has a low but positive log-lambda, are predicted to have negative population growth rates (Fig. 4). 


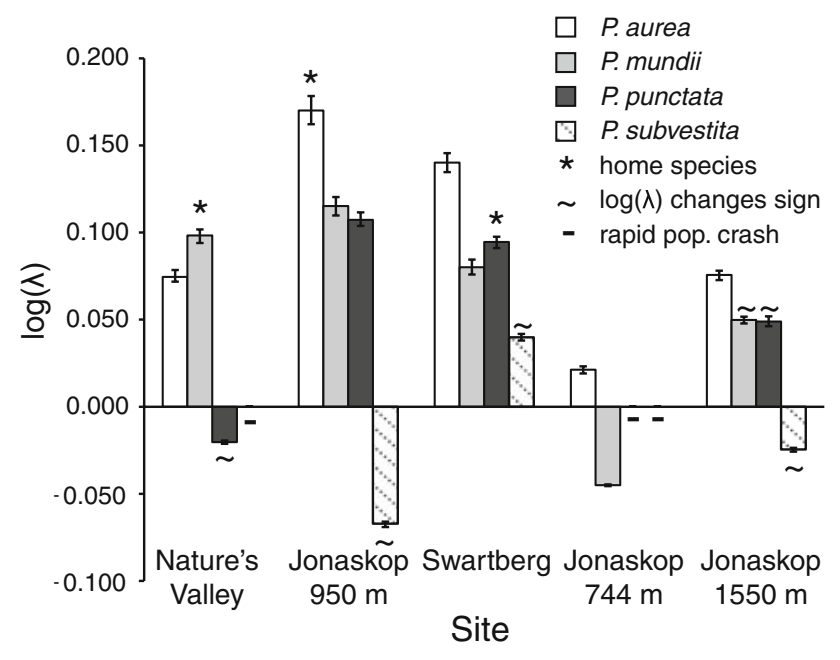

Fig. 4 Predicted population growth rates for the white protea species. Asterisks indicate the bars for the "home" species for each site. Error bars represent the 2.5 and 97.5 quantiles for the log growth rates from 200 simulations

Across all species and sites, the demographic models predict that the three CFR native species would be able to maintain positive population growth rates at sites beyond their current distribution limits (Fig. 4). The non-native $P$. subvestita, by contrast, was predicted to decline to extinction at all sites, though for the Swartberg and Jonaskop 950-m sites, the sign of predicted $\log (\lambda)$ became slightly positive under the most favorable assumptions for demographic rates (Fig. 4). Sensitivity analysis showed that for most species-site combinations, $\log (\lambda)$ was most sensitive to adult mortality rates and germination (Supplementary Table 1:2).

Population genetics results

Genetic geographic structure among populations was significant but modest, with the Bayesian estimator for interpopulation structure $\theta_{B}=0.044$, and significantly different from 0, and Slatkin's Rst consistent at 0.0422 (Epperson 2003). Within populations, genetic correlation among individuals as measured by Moran's I declined rapidly with distance, reaching effectively 0 within 100-200 m (Fig. 5).

\section{Discussion}

It is usually impossible to attribute an unambiguous cause for the absence of a species from some area from observations alone. Ecologists often assume, for example in nichebased distribution models, that observed absence reflects current environmental limitation, but this is not necessarily the case (Van Teeffelen and Ovaskainen 2007). A location might be suitable but remain unoccupied due to dispersal

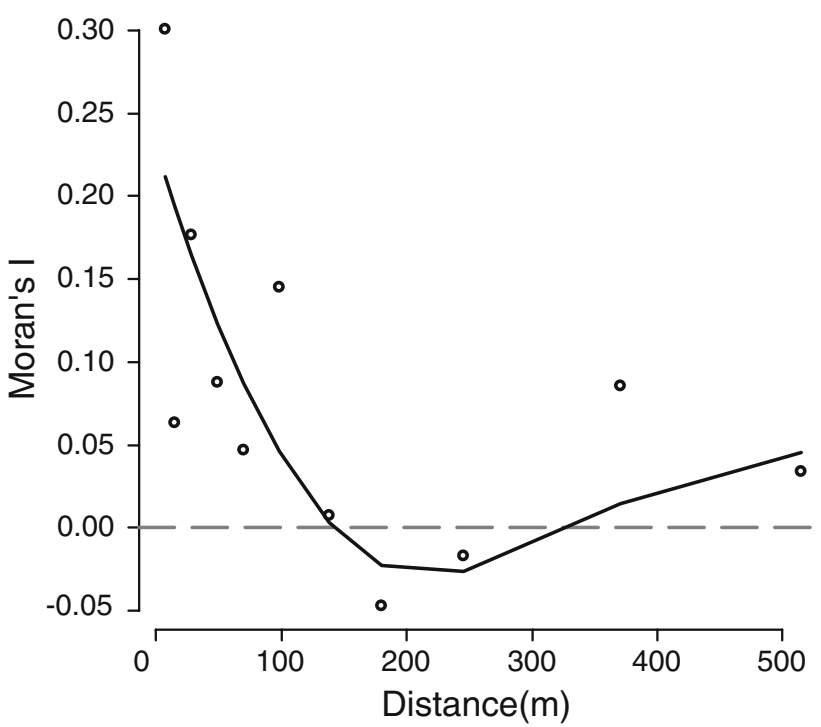

Fig. 5 Correlogram showing decline with distance of genetic correlation among Protea punctata individuals within populations. The dots represent Moran's I for pairs of individuals in a corresponding distance bin; the solid line is a fitted loess curve

limitation, to land use history, or past environmental conditions (Ibanez et al. 2007; Latimer et al. 2006; Van Teeffelen and Ovaskainen 2007). Because of this basic ambiguity in species distribution data and in models based on them, it is important to supplement observational data with experiments in order to explain species distribution patterns, and the diversity patterns they generate-to do, in effect, "experimental biogeography" (Gaston 2003).

In the CFR, high species diversity is associated with high geographic species turnover within many lineages. For the species group studied here, the white proteas, distribution models have been used to infer that the species could overlap more than they are observed to do, based on predictions of their potential ranges (Latimer et al. 2006). But if we remove dispersal barriers by reciprocally transplanting the species, would they really perform well beyond their current distribution limits?

This experiment reveals that environmental limitation plays a role in preventing these species from co-existing completely, but cannot fully account for their nearly complete allopatry. Both the comparisons of individual performance measurements and the integrated demographic results demonstrate that the species have some degree of "home-site advantage," presumably reflecting adaptation to local conditions. In particular, two of the native species, $P$. aurea and $P$. mundii, perform best at their home sites, and are predicted to have higher population growth rates than the other species in the clade at those sites. The third native species, the higher-elevation species $P$. punctata, appears unable, due to germination failure, to coexist with its lower-elevation relative $P$. mundii in part of $P$. mundii's 
distribution. In contrast to the native species, the non-native $P$. subvestita performed substantially worse than the native species, and the demographic models predict it would be unable to maintain population growth at any of the sites.

At the same time, the experiment strongly suggests that environmental contrasts do not fully account for the absence of co-occurrence in these species. Each of the three CFR native species was predicted by demographic models to be capable of maintaining positive population growth rates at sites outside their current distribution limits (Fig. 4). One of the native species, P. aurea, is predicted to be suitable for all sites. These findings are consistent with other studies that have found that many, even well-dispersed plant species, such as north-temperate forest trees, do not occupy distributions that are fully in equilibrium with abiotic environmental conditions (Svenning and Skov 2004; Prince and Carter 1985). They also complement previous research showing that poorly dispersed CFR Proteaceae occupy less of their predicted potential ranges than well-dispersed species (Schurr et al. 2007).

Both population genetics-based inference and mechanistic dispersal models for $P$. punctata produce similar estimates of mean dispersal for the species on the order of $10 \mathrm{~m}$ (Latimer 2006; Schurr et al. 2005, 2007). The relatively small genetic neighborhood within populations (Fig. 5) corresponds to short mean gene dispersal distances, which combine both gene and pollen flow within the population. The short combined gene flow strongly suggests that both seeds and pollen are moving relatively short distances within populations - if either pollen grains or seeds were moving much farther, the estimate would be increased. So while we cannot pin down a precise seed dispersal distance without direct parental assignment, we can infer that seed dispersal within populations we sampled is short. This short average dispersal distance, coupled with the hard barrier to seed dispersal imposed by fire size (unburned vegetation at the edges of fires prevents further seed dispersal) (Bond 1984, 1988; Schurr et al. 2005), suggests that infrequent dispersal prevents these species from exchanging large numbers of immigrant seeds.

While $P$. punctata is a species we found more limited by environmental factors than $P$. aurea or $P$. mundii, the factors that keep dispersal distances short for $P$. punctata (seed morphology, roughness of terrain) also affect $P$. aurea and $P$. mundii. So if we generalize the gene dispersal results from $P$. punctata to these species, it appears that low migration rates may have contributed to allopatric and parapatric speciation in this clade (Cowling and Lombard 2002; Rieseberg and Willis 2007). The relatively low estimates of genetic differentiation among populations, in contrast, suggest a mechanism is operating to maintain significant gene migration among populations. Such long-distance gene flow is consistent with what is known about the movement patterns of the species' primary pollinator, the Cape sugarbird (Promerops cafer), which has been observed in markrecapture studies to travel hundreds of kilometers in a year (Calf et al. 2003; Hockey et al. 2005).

This experiment, with its relatively short time duration (our permit to conduct the experiment restricted us to 2 years, to ensure that no plants flowered and produced pollen or seed that could affect local populations), and its limitation to a single exemplary clade, cannot conclusively answer the question of what controls distributions in this clade, or, even more broadly, pin down the role of environmental gradients in species turnover in the CFR. In particular, we cannot determine with high confidence whether the absence of species from sites that are predicted by demographic models to be suitable for them is due to competitive interactions or other population-dynamic factors, to dispersal limitation, or to hybridization and introgression at species boundaries. We have presented evidence showing the pattern is consistent with evidence of dispersal limitation. There is also evidence against some other potential explanations. Pollinator specialization cannot be a strong influence, since the primary pollinators of all the species occur across the region (Collins and Rebelo 1985). The distributions of the clade's dominant insect herbivores and pathogens are unknown; if strong differences in plant performance turned out to be associated with differential herbivory or disease rates, we expected to be able to observe and document this by examining sick, heavily browsed, and dead plants. In fact there was little herbivory on the plants, and what little did occur was not systematically different across sites (A. M. Latimer, personal observation, August 2003; Latimer 2006).

But other dynamics may well play a role. Competitive interactions among the species are another possible mechanism that might restrict coexistence. We have explored the role of competitive interactions by planting species together in variable-density plots in pure stands and in two-species mixtures with their neighboring species (Latimer 2006). We found that species generally performed better (growth, mortality) and experienced less water stress in mixtures, and therefore that competition at the seedling stage seems unlikely to account for the species' failure to coexist (Latimer 2006). It is nonetheless possible that differential performance and/or direct competitive interactions later in life could be influential, as has been suggested in some observational studies (Bond et al. 1995). The higher modeled demographic rates of two species at their home sites could also lead them to overwhelm colonists demographically, particularly if colonizers were subject to Allee effects.

This experiment provides evidence that there is an aridity-related limit on the distributions of the white proteas as a group, and thus demonstrates that the valleys between many populations under current, historically arid conditions 
may pose a dispersal barrier to the species. Only $P$. aurea was predicted to be able to maintain a marginally positive population growth rate at the Jonaskop 744-m site, which occurs at the warmer, drier end of the distributions of the more drought-tolerant protea species (Rebelo 2001). Seed germination and seedling mortality during the first year appear to be the life history stages at which this drought limitation operates, and the effect of water limitation on the plants was evident in the stable isotope ratio values of surviving individuals (Supplementary Fig. 2:3). The sensitivity of population growth rates to germination supports the widely held view that for the serotinous woody species that dominate much of the fynbos vegetation, establishment and survival of the first year's drought are critical life history stages (Bond 1984; Cowling and Lombard 2002). The high sensitivity of population growth to adult mortality suggests that drought or disease would have a potentially catastrophic effect on populations of these serotinous plants if they produced high death rates in a particular interval between fires. In the field, however, we observe that variability in adult mortality is quite low, while variability in germination and seedling survival is high. We conclude that under the observed range of environmental conditions, regeneration appears to be the life stage at which population performance responds most sensitively to environmental variation.

The failure of these species to thrive at the most arid transplant site supports the view that the topography of the region, the short dispersal of the plants, and the limits to dispersal imposed by fire edges may play a key role in the high levels of endemism and species turnover in the region-making diversity patterns in the region in some ways more similar to those in an archipelago than a continental area (Linder 2003, 2005). Our results experimentally confirm the predictions of distribution models (Latimer 2006; Latimer et al. 2006) that under current and projected future conditions, many valleys form barriers to dispersal for these and many other CFR Proteaceae (Midgley et al. 2002; Thomas et al. 2004), contributing to low overall levels of migration in the region (Latimer et al. 2005; Schurr et al. 2007). Whether lineage splitting in evolutionary time is enhanced by these valleys themselves, which were probably often wetter during much of the Pleistocene, or by plant dispersal traits and their interaction with fire-driven recruitment, or by shorter generation times relative to resprouting species (Wisheu et al. 2000), remain open questions. Results from this experiment suggest that short dispersal, which ensures that colonizing populations are relatively infrequent and small (Schurr et al. 2007), may play an important role in maintaining non-overlapping distributions in the group. If conditions aridify further under climate change as predicted by most general circulation models (Christensen et al. 2007), these barriers may slow or prevent distribution shifts in these species, leaving them vulnerable to stranding in shrinking, relictual distribution patches (Midgley et al. 2003; Thomas et al. 2004).

Acknowledgments We acknowledge generous assistance and support from many at South African National Biodiversity Institute, including especially the Protea Atlas Project, Ismail Ibrahim and Deryck DeWitt, and thank field assistant Kyle Noonan. We thank CapeNature and Mountains to Oceans for granting site access. This work was funded by NSF grants DEB 008901 and 056320, an NSF graduate research fellowship to A. M. Latimer, and the University of Connecticut and University of California Davis. We are grateful to Richard Cowling, Robin Chazdon, Robert Colwell, Carl Schlichting, Ines Ibañez, and Robert Dunn for their comments on experimental design and manuscript drafts, and to Jane Carlson, Rachel Prunier, and Res Altwegg for access to unpublished demographic data. The experiments reported comply with the current laws of the country in which they were performed.

Open Access This article is distributed under the terms of the Creative Commons Attribution Noncommercial License which permits any noncommercial use, distribution, and reproduction in any medium, provided the original author(s) and source are credited.

\section{References}

Agenbag L (2006) Phenological responses of selected plant functional types on an altitudinal gradient in the southwestern Cape. M.Sc. thesis, Botany, University of Stellenbosch, Stellenbosch

Anderson D (1996) The competitive dynamics of two protea shrubs growing in a mixed fynbos stand. Ph.D. dissertation, Botany, University of Cape Town, Cape Town

Angert AL (2006) Demography of central and marginal populations of monkey flowers (Mimulus cardinalis and M-lewisii). Ecology 87:2014-2025

AvianDemography Unit (2006) Cape sugarbird Promerops cafer. In: SAFRING results. Department of Statistical Sciences. University of Cape Town, Cape Town

Barraclough TG (2006) What can phylogenetics tell us about speciation in the Cape flora? Divers Distrib 12:21-26

Beckage B, Clark JS (2003) Seedling survival and growth of three forest tree species: the role of spatial heterogeneity. Ecology 84:1849-1861

Bond WJ (1984) Fire survival of Cape Proteaceae-influence of fire season and seed predators. Vegetatio 56:65-74

Bond WJ (1988) Proteas as 'tumbleseeds': wind dispersal through the air and over soil. S Afr J Bot 54:455-460

Bond WJ, Midgley JJ (2001) Ecology of sprouting in woody plants: the persistence niche. Trends Ecol Evol 16:45-51

Bond WJ, Cowling RM, Richards MB (1992) Competition and coexistence. In: Cowling RM (ed) The ecology of the fynbos. Nutrients, fire and diversity. Oxford University Press, Cape Town, pp 206-225

Bond WJ, Maze KE, Desmet P (1995) Fire life histories and the seeds of chaos. Ecoscience 2:252-260

Brown NAC, Botha PA (2004) Smoke seed germination studies and a guide to seed propagation of plants from the major families of the Cape Floristic Region, South Africa. SAfr J Bot 70(4):559-581

Calf KM, Downs CT, Cherry MI (2003) Territoriality of Cape Sugarbirds (Promerops cafer) between and within breeding seasons. Ostrich 74:125-128

Caswell H (2001) Matrix population models: construction, analysis, and interpretation. Sinauer, Sunderland 
Christensen JH, et al. (2007) Regional climate projections. In: Solomon S, et al. (eds) Climate change 2007: the physical science basis. Contribution of Working Group I to the Fourth Assessment Report of the Intergovernmental Panel on Climate Change. Cambridge University Press, Cambridge

Collins BG, Rebelo AG (1985) Pollination biology of the Proteaceae in Australia and southern Africa. Aust J Ecol 12:387-421

Cowling RM (1990) Diversity components in a species-rich area of the Cape Floristic Region. J Veg Sci 1:699-710

Cowling RM, Lombard AT (2002) Heterogeneity, speciation/extinction history and climate: explaining regional plant diversity patterns in the Cape Floristic Region. Divers Distrib 8:163-179

Cowling RM, Proches S (2005) Patterns and evolution of plant diversity in the Cape Floristic Region. In: Friis I, Balslev H (eds) Plant diversity and complexity patterns. Local, regional and global dimensions, vol 55. The Royal Danish Academy of Sciences and Letters, Copenhagen, pp 273-288

Cowling RM, Rundel PW, Lamont BB, Arroyo MK, Arianoutsou M (1996) Plant diversity in Mediterranean-climate regions. Trends Ecol Evol 11:362-366

Ellis AG, Weis AE (2006) Coexistence and differentiation of 'flowering stones': the role of local adaptation to soil microenvironment. J Ecol 94:322-335

Epperson BK (2003) Geographical genetics. Princeton University Press, Princeton

Forbis TA, Doak DF (2004) Seedling establishment and life history trade-offs in alpine plants. Am J Bot 91:1147-1153

Forsyth GG, van Wilgen BW (2007) An analysis of fire records from protected areas in the Western Cape. CSIR, Stellenbosch

Gaston KJ (2003) The structure and dynamics of geographic ranges. Oxford University Press, New York

Goldblatt P (1997) Floristic diversity in the Cape flora of South Africa. Biodivers Conserv 6:359-377

Goldblatt P, Manning J (2000) Cape plants: a conspectus of the Cape flora of South Africa. National Botanical Institute of South Africa, Cape Town

Goldblatt P, Manning JC (2002) Plant diversity of the Cape Region of southern Africa. Ann Mo Bot Gard 89:281-302

Hardy OJ, Vekemans X (2002) SPAGeDi: a versatile computer program to analyse spatial genetic structure at the individual or population levels. Mol Ecol Notes 2:618-620

Hockey P, Dean WRJ, Ryan PG (2005) Roberts birds of southern Africa, 7th edn. Trustees of the South African Bird Book Fund, Cape Town

Holsinger KE, Lewis PO (2003) Hickory: a package for analysis of population genetic data, v. 1.0. Department of Ecology and Evolutionary Biology. University of Connecticut, Storrs

Ibanez I, Clark JS, LaDeau S, Hille Ris Lambers J (2007) Exploiting temporal variability to understand tree recruitment response to climate change. Ecol Monogr 77:163-177

Latimer AM (2006) Environmental and geographical controls on species distributions: a case study on proteas of the Cape Floristic Region. Ph.D. dissertation, Ecology and Evolutionary Biology, University of Connecticut, Storrs

Latimer AM, Silander JA, Cowling RM (2005) Neutral ecological theory reveals isolation and rapid speciation in a biodiversity hot spot. Science 309:1722-1725

Latimer AM, Wu S, Gelfand AE, Silander JA (2006) Building statistical models to analyze species distributions. Ecol Appl 16:33-50

Linder HP (1985) Gene flow, speciation, and species diversity patterns in a species-rich area: the Cape flora. In: Vrba ES (ed) Species and speciation, vol 4. Transvaal Museum Monographs, Pretoria, pp $53-57$

Linder HP (2003) The radiation of the Cape flora, southern Africa. Biol Rev 78:597-638
Linder HP (2005) Evolution of diversity: the Cape flora. Trends Plant Sci 10:536-541

Linder HP, Mann DM (1998) The phylogeny and biogeography of Thamnochortus (Restionaceae). Bot J Linn Soc 128:319-357

Linder HP, Dlamini T, Henning J, Verboom GA (2006) The evolutionary history of Melianthus (Melianthaceae). Am J Bot 93:10521064

Lotz CN, Nicholson SW (1996) Sugar preferences of a nectarivorous passerine bird, the lesser double-collared Sunbird (Nectarinia chalybea). Funct Ecol 10:360-365

Midgley GF, Hannah L, Millar D, Rutherford MC, Powrie LW (2002) Assessing the vulnerability of species richness to anthropogenic climate change in a biodiversity hotspot. Glob Ecol Biogeogr 11:445-451

Midgley GF, Hannah L, Millar D, Thuiller W, Booth A (2003) Developing regional and species-level assessments of climate change impacts on biodiversity in the Cape Floristic Region. Biol Conserv 112:87-97

Morris WF, Doak DF (1998) Life history of the long-lived gynodioecious cushion plant, Silene acaulis (Caryophyllaceae), inferred from size-based population projection matrices. Am J Bot $85: 784-793$

Norton LR, Firbank LG, Scott A, Watkinson AR (2006) Characterising spatial and temporal variation in the finite rate of population increase across the northern range boundary of the annual grass Vulpia fasciculata. Oecologia 144:407-415

Pinheiro JC, Bates DM (2000) Mixed-effects models in S and S-PLUS. Springer, New York

Prince SD, Carter RN (1985) The geographical distribution of prickly lettuce (Latuca serriola): III. Its performance in transplant sites beyond its distribution limits in Britain. J Ecol 73:49-64

Rebelo AG (2001) Proteas: a field guide to the proteas of Southern Africa, 2nd edn. Fernwood Press, Vlaeberg

Rebelo AG (2006) Protea atlas project website. http://protea. worldonline.co.za/default.htm

Reeves G (2001) Radiation and macroevolutionary ecology of the African genus Protea L. (Proteaceae). Ph.D. dissertation, Department of Biological Sciences, Imperial College, London

Richards MB, Stock WD, Cowling RM (1995) Water relations of seedlings and adults of two fynbos Protea species in relation to their distribution patterns. Funct Ecol 9:575-583

Richards MB, Cowling RM, Stock WD (1997a) Soil factors and competition as determinants of the distribution of six fynbos Proteaceae species. Oikos 79:394-406

Richards MB, Stock WD, Cowling RM (1997b) Soil nutrient dynamics and community boundaries in the fynbos vegetation of South Africa. Plant Ecol 130:143-153

Richardson JE, et al. (2001) Rapid and recent origin of species richness in the Cape flora of South Africa. Nature 412:181-183

Rieseberg LH, Willis JH (2007) Plant speciation. Science 317:910914

Rouget M, Richardson DM, Cowling RM, Lloyd JW (2003) Current patterns of habitat transformation and future threats to biodiversity in terrestrial ecosystems of the Cape Floristic Region, South Africa. Biol Conserv 112:63-85

Schulze RE (1997) South African atlas of agrohydrology and climatology. Technical report. Report TT82/96. Water Resource Commission, Pretoria

Schurr FM, Bond WJ, Midgley GF, Higgins SI (2005) A mechanistic model for secondary seed dispersal by wind and its experimental validation. J Ecol 93:1017-1028

Schurr FM, Midgley GF, Reeves G, Poschlod P, Higgins SI (2007) Colonization and persistence ability explain the extent to which plant species fill their potential range. Glob Ecol Biogeogr $16: 449-459$ 
Silander JA (1983) Demographic variation in the Australian desert cassia under grazing pressure. Oecologia 60:227-233

Simmons MT, Cowling RM (1996) Why is the Cape Peninsula so rich in plant species? An analysis of the independent diversity components. Biodivers Conserv 5:551-573

Skalski JR, Ryding KE, Millspaugh JJ (2005) Wildlife demography: analysis of sex, age, and count data. Academic, San Diego

Snedecor GW, Cochran WG (1989) Statistical methods, 8th edn. Iowa State University Press, Ames

Stokes KE, Bullock JM, Watkinson AR (2004) Population dynamics across a parapatric range boundary: Ulex gallii and Ulex minor. J Ecol 92:142-155

Svenning JC, Skov F (2004) Limited filling of the potential range in European tree species. Ecol Lett 7:565-573

Thomas CD, et al. (2004) Extinction risk from climate change. Nature 427:145-148
Tuljapurkar S (1997) Stochastic matrix models. In: Tuljapurkar S, Caswell H (eds) Structured-population models in marine, terrestrial, and freshwater systems. Chapman \& Hall, New York

Turnbull B (1974) Nonparametric estimation of a survivorship function with doubly censored data. J Am Stat Assoc 69:169-173

Van Teeffelen AJA, Ovaskainen O (2007) Can the cause of aggregation be inferred from species distributions? Oikos 116:4-16

Venables WN, Ripley BD (2002) Modern applied statistics with S, 4th edn. Springer, New York

Wisheu IC, Rosenzweig ML, Olsvig-Whittaker L, Shmida A (2000) What makes nutrient-poor mediterranean heathlands so rich in plant diversity? Evol Ecol Res 2:935-955

Yeaton RI, Bond WJ (1991) Competition between two shrub species: dispersal distances and fire promote coexistence. Am Nat 138:328-341 